NASCIMENTO, Anna Melissa Marcondes; HUDSON, Maria Rita Cerqueira; SILVA, Antonio Wardison Canabrava. A base Constitucional como mecanismo de justiça para uma economia solidária.

\title{
A base Constitucional como mecanismo de justiça para uma economia solidária
}

The Constitutional fundament as a justice mechanism for a solidary economy

\section{Antonio Wardison Canabrava da Silva \\ Orientador \\ wardison@hotmail.com}

Doutor em Filosofia pela Pontifícia Universidade Católica de São Paulo - PUC-SP. Pró-Reitor de Extensão, Ação Comunitária e Pastoral do Centro Universitário Salesiano de São Paulo - UNISAL.

\section{Anna Melissa Marcondes Nascimento annamel2000@gmail.com}

Graduanda em Direito pelo Centro Universitário Salesiano de São Paulo UNISAL.

\section{Maria Rita Cerqueira Hudson} mrita5050@gmail.com

Graduanda em Direito pelo Centro Universitário Salesiano de São Paulo UNISAL.

\section{Resumo}

A Constituição de 1988, fruto da situação histórico-política, bem como econômico-cultural do Brasil, busca promover e assegurar a justiça, como fundamento de igualdade entre seus cidadãos, seja do ponto de vista dos seus direitos fundamentais, seja da ação dos indivíduos, em uma perspectiva de empreendimento, no Estado de Direito. Tal concepção acentua a necessidade de uma economia solidária, capaz de criar e oportunizar políticas e ações em prol do bem coletivo e do direito à liberdade individual.

Palavras-chave: Justiça; economia; solidariedade; constituição; direito.

\begin{abstract}
The 1988 Constitution, the result of the historical-political as well as economic-cultural situation in Brazil, seeks to promote and ensure justice, as a basis for equality among its citizens, both from the point of view of their fundamental rights and the action of individuals, from an entrepreneurial perspective, under the rule of law. This conception emphasizes the need for a Solidary Economy, capable of creating and providing policies and actions for the benefit of the collective good and the right to individual freedom.
\end{abstract}

Keywords: Justice; economy; solidarity; constitution; law. 
NASCIMENTO, Anna Melissa Marcondes; HUDSON, Maria Rita Cerqueira; SILVA, Antonio Wardison Canabrava. A base Constitucional como mecanismo de justiça para uma economia solidária.

\section{Introdução}

Idealizar uma economia solidária consiste em analisar o papel da justiça em seu escopo apaziguador de desigualdades sociais. O exercício da justiça no ordenamento jurídico se faz presente em artigos e princípios enumerados na Constituição Federal de 1988, de forma a prezar pela manutenção de direitos inerentes ao ser humano. Dentre eles, a dignidade da pessoa humana, que se torna um reflexo da efetivação de garantias de uma vida de qualidade. Esta, do ponto de vista jurídico, é possível por meio de um desenvolvimento socioeconômico com pautas solidárias.

Essa economia solidária, que busca aumentar a igualdade social, não conteria uma relação de dominação entre os polos, que seriam equitativos. Esta relação se demonstraria presente através de políticas e ações de caráter colaborativo, maximizando a quantidade e qualidade de trabalho, sem visar apenas o lucro. Da perspectiva jurídica, tal premissa seria um reforço para ações igualitárias. Ora, de acordo com Singer, a própria formação da economia solidária tem base na democracia e na igualdade (Singer, [s.d]).

Objetivando a concretização da economia solidária pela justiça, no Estado brasileiro constam diversos órgãos voltados à promoção e manutenção de empreendimentos solidários, visando um desenvolvimento sustentável. Os papéis das entidades e empresas são os de fornecedoras de produtos e serviços acessíveis à população, bem como de empregos, levando à propagação de qualidade de vida e efetivação do princípio da dignidade da pessoa humana.

Nessa perspectiva, este artigo tem a finalidade de explicitar e, com isso, analisar a Constituição como mecanismo de justiça para uma economia solidária, de tal forma que a justiça deva ser o parâmetro e sustentáculo para a instauração de uma ação solidária no plano da economia. Estruturado em três partes, o texto apresentará: o conceito de justiça com base na Constituição de 1988; a perspectiva teórica de uma economia solidária e suas implicações e o viés da economia solidária no Brasil.

\section{Conceito de Justiça no âmbito constitucional}

O termo "justiça" configura uma palavra plurissignificativa, advindo do latim "justicia" (direito, administração da lei), que deriva de "justus" (correto, justo), procedendo de "jus" (lei, direito legal) (Rodriguez, 2016). Enquanto ideal buscado pelo Direito, o conceito "justiça" exerce grande importância como condutor da harmonia social, no sentido em que funciona 
NASCIMENTO, Anna Melissa Marcondes; HUDSON, Maria Rita Cerqueira; SILVA, Antonio Wardison Canabrava. A base Constitucional como mecanismo de justiça para uma economia solidária.

como um apaziguador e inibidor de conflitos de base ética, moral, cultural, social, ou qualquer que seja seu gênero.

Nesse contexto, a justiça é percebida na Constituição Federal como um atributo essencial para a formação e concretização de direitos fundamentais e de garantias coletivas, às vezes valendo-se como um valor intrínseco na letra da lei. Dessa forma, os artigos ali enunciados exercem o papel de concretizar o valor abstrato da justiça em direito material.

A Constituição de 1988 foi escrita após um período de vinte e um anos de ditadura militar, quando o Brasil passava por um período de redemocratização. Sob esse regime, inúmeras violações aos direitos humanos foram cometidas; as injustiças feitas contra o povo, desrespeitando suas liberdades individuais, trouxeram uma característica de grande proteção social na Constituição que o sucedeu. Na Constituição, muitas são as referências feitas à justiça, especialmente por ela ter sido tão fragilizada durante a ditadura, servindo agora como base para muitos de seus institutos. É, como indicou Ulysses Guimarães, uma busca pelo avanço das necessidades sociais e um alargamento do exercício da democracia (Guimarães, 1988).

No horizonte da Constituição, não há uma definição clara sobre justiça, mas é possível entendê-la com base em uma análise a partir de alguns de seus artigos e princípios. Inicialmente, a respeito de seus princípios, vale ressaltar dois: o Princípio de Acesso à Justiça e Dignidade da pessoa humana. Na perspectiva de Habermas, conforme citado por Oscar Vilhena Vieira (1997), para se validar a Constituição, é fundamental que ela se dignifique como "ordem justa". No sentido dado pelo Princípio de Acesso à Justiça, refere-se à possibilidade de todo cidadão reivindicar seus direitos perante o Estado, por meio do judiciário. Seria possível, então, definir justiça, a partir desse princípio, como a possibilidade de o indivíduo se defender, mediante recursos do Estado, contra abusos feitos por outros entes da sociedade, sejam eles econômicos, físicos ou morais. Justiça, nesse sentido, teria uma definição voltada para a execução dos direitos através do acesso ao judiciário, depois de o indivíduo ter um de seus direitos violados ou de forma a concretizá-lo. Já no sentido do princípio da Dignidade da pessoa humana, justiça seria um conceito muito mais empírico: são garantias dadas à pessoa para que ela tenha uma vida com qualidade e respeito aos seus direitos fundamentais.

Em seu Título II, Capítulo I, art. 5, a Constituição determina a igualdade de todos os cidadãos, sem nenhum tipo de distinção ou violação ao direito à vida, à liberdade, à segurança, à igualdade e à propriedade (Brasil, 1988). Constata-se, assim, um esforço da Constituição em fazer valer a justiça perante a sociedade através da manutenção de direitos inerentes ao ser humano, no sentido prático. 
NASCIMENTO, Anna Melissa Marcondes; HUDSON, Maria Rita Cerqueira; SILVA, Antonio Wardison Canabrava. A base Constitucional como mecanismo de justiça para uma economia solidária.

Já no Título II da Constituição Federal, a justiça permeia os direitos sociais assegurados, a saber: a educação, a saúde, a alimentação, o trabalho, a moradia, o transporte, o lazer, a segurança, a previdência social, a proteção à maternidade e à infância, a assistência aos desamparados. Todos são meios de se buscar a justiça e meios através dos quais a justiça se faz presente na relação Estado - População (Brasil, 1988).

No Título IV da Constituição Federal, ao tratar da organização dos poderes, a justiça aparece como fundamento em grande parte da construção de órgãos e as respectivas funções que lhe são atribuídas. No Capítulo III, por exemplo, a sistemática do Poder Judiciário tem sua base extraída da própria concepção de justiça e da resolução de conflitos sociais, que são realizados pelo conjunto de representantes que o compõe: juízes, promotores etc. (Brasil, 1988).

No Título VIII da Constituição, a respeito da ordem social, o valor da justiça é evidenciado na disposição de direitos referentes a pilares da dignidade da pessoa humana, tais como saúde, educação, ciência, comunicação entre outros (Brasil, 1988).

Relacionar a Constituição Federal, como uma ferramenta de propagação de justiça, à economia solidária é fundamental para se reconhecer a justiça como um pilar da solidariedade. Aquela nasceu para garantir a igualdade entre as pessoas, equidade diante das diferenças sociais, econômicas, políticas e humanas. Já a solidariedade evidencia-se como um resultado do desenvolvimento da justiça.

\section{Economia solidária}

Economia solidária é um sistema de produção em que as partes atuantes se autoorganizam e se autoadministram, de forma a ocuparem posições igualitárias e que se complementam entre si, por meio de ações cooperativas. Em outras palavras, na economia solidária não há o polo soberano que detém poder sobre o outro. Ambos se autodeterminam em condições de equivalência, sendo a produção, distribuição e comercialização alinhadas em um panorama colaborativo. Na definição dada pelo Sistema Nacional de Informações em Economia Solidária, são as organizações solidárias as que apresentam as seguintes características:

Coletivas - serão consideradas as organizações suprafamiliares, singulares e complexas, tais como: associações, cooperativas, empresas autogestionárias, grupos de produção, clubes de trocas, redes etc.; cujos participantes ou sócios(as) são trabalhadores(as) dos meios urbano e rural que exercem coletivamente a gestão das atividades, assim como a alocação dos resultados; permanentes, incluindo os empreendimentos que estão em funcionamento e aqueles que estão em processo de implantação, com o grupo de participantes constituído e as atividades econômicas definidas; que disponham ou não de registro legal, prevalecendo a existência real e que realizam 
NASCIMENTO, Anna Melissa Marcondes; HUDSON, Maria Rita Cerqueira; SILVA, Antonio Wardison Canabrava. A base Constitucional como mecanismo de justiça para uma economia solidária.

atividades econômicas de produção de bens, de prestação de serviços, de fundos de crédito (cooperativas de crédito e os fundos rotativos populares), de comercialização (compra, venda e troca de insumos, produtos e serviços) e de consumo solidário. (Senaes, 20013, p.1)

Na contextualização de Singer, a economia solidária surgiu com operários, no século XIX, como resposta à desigualdade social e pobreza geradas pela difusão "desenfreada" das máquinas a vapor, sendo "tentativas por parte de trabalhadores de recuperar trabalho e autonomia econômica, aproveitando as novas forças produtivas" (Singer, [s.d], p.4). Além disso, ele ainda afirma que "alguma solidariedade, alguma interação desinteressada e altruísta é indispensável à reprodução de qualquer sociedade" (Singer, 2001, p.1). Diferencia, ainda, economia capitalista da economia solidária no sentido que, na primeira, o modo de produção segue princípios de propriedade e liberdade individuais; na segunda, de propriedade coletiva ou associada do capital e do direito à liberdade coletiva (Singer, 2002, p.10).

Assim, para Singer, o capitalismo é regido pela competição em âmbito econômico. Afinal, esta competição deveria ser essencial para o equilíbrio da oferta e demanda, nas relações particulares, como nos núcleos familiares, de amizade ou mesmo relações entre colegas de trabalho (Singer, 2001). Hoje, porém, este equilíbrio é antieconômico, como demonstrado por Singer: a competição é realizada entre empresas massivas, forçando os consumidores domésticos a escolher produtos pouco diversificados e em faixa semelhante de preço, disponibilizados por poucas marcas, criando um grande desnível entre o grande capital e o consumidor final (Singer, 2001).

Quando se fala em justiça como base para uma economia solidária, ressalta-se que, na criação desta, os operários buscam maximizar a quantidade e qualidade de trabalho, não o lucro, nas empresas solidárias (Singer, [s.d], p.4). Ou seja, sua produção é colaborativa e visa o bemestar dos trabalhadores. Para buscar este equilíbrio, é necessária uma justa cooperação entre os produtores e consumidores e a proteção do Estado contra a desigualdade social, conforme previsto no artigo $3^{\circ}$, III, da Constituição Federal, como um dos objetivos fundamentais da República Federativa do Brasil (Brasil, 1988). O Estado, como provedor de mecanismos para aproximar o povo da Justiça, também deve prever formas em sua lei de tornar a economia justa. Justiça e economia solidária deverão ser, portanto, complementares, para promover um crescimento da igualdade social e acessibilidade ao consumo no país.

Entendendo que a solidariedade é resultado de um desenvolvimento de justiça em um país, a economia solidária se faz presente na manutenção de uma vida digna e de qualidade à população, no que tange ao suprimento das necessidades coletivas e medidas impeditivas à desigualdade. 
NASCIMENTO, Anna Melissa Marcondes; HUDSON, Maria Rita Cerqueira; SILVA, Antonio Wardison Canabrava. A base Constitucional como mecanismo de justiça para uma economia solidária.

Desta forma, quais mecanismos da Constituição Federal dão base para a economia solidária? Os princípios que regem a ordem Eeconômica no Brasil estão elencados no seu artigo 170, e entre eles, os princípios da Livre Concorrência, Defesa do Consumidor e Redução das Desigualdades Regionais e Sociais (Brasil, 1988). Já foi ressaltado que, na criação do conceito de economia solidária, busca-se dar autonomia econômica aos trabalhadores e fornecer igualdade social (Singer, [s.d]). Além disso, partindo do princípio da livre concorrência, Singer já demonstrou que ela é feita principalmente pelas grandes empresas, excluindo a participação das menores e aumentando a desigualdade econômica. Esta falta de concorrência acaba também afetando a defesa do consumidor, pois há menos diversificação de produtos e preços para acesso dos compradores (Singer, [s.d]). A Constituição Federal ainda prevê, em seu artigo 173, §4º a repressão dos abusos de poder econômico (Brasil, 1988).

A economia solidária, ainda, se solidifica sob o prisma de alinhar os direitos fundamentais inerentes ao cidadão através de outros mecanismos legalmente estabelecidos. São esses os estabelecidos no Título II, Dos Direitos e Garantias Fundamentais. O art. 5º por exemplo, reforça o ideal de igualdade de todos perante a lei, no sentido em que busca alinhá-la à segurança, liberdade e propriedade, essenciais pilares de uma vida humana digna.

Também refletem a economia solidária os artigos instituídos no Título VIII, Da Ordem Social. A exemplificar, o art. 195, ao determinar que a seguridade social será financiada por toda a sociedade, de forma direta e indireta, faz referência ao ideal de solidariedade. Ao assegurar direitos, tais como a saúde, segurança e educação, evidencia-se um esforço por parte do legislador de se fazer valer ações que visam o bem-estar coletivo por meio de ferramentas colaborativas, evidenciando assim um caráter economicamente solidário (Brasil, 1988). Vê-se, portanto, que a economia solidária deveria ser promovida, afinal, sua própria formação tem base na igualdade e democracia (Singer, [s.d]).

De acordo com Euclides André Mance (2002), os critérios para a formação de redes de colaboração solidária são pautados na ausência de exploração de trabalho, opressão política ou dominação cultural; na preservação do equilíbrio ecológico dos ecossistemas; no direcionamento do excedente para a expansão da própria rede; e na autodeterminação dos fins e autogestão dos meios, em espírito de cooperação e colaboração.

Resultado de anos de um desenvolvimento capitalista, a economia brasileira atualmente se configura em um viés competitivo, fortalecendo cada vez mais a desigualdade e as injustiças sociais e econômicas. O professor Paul Singer (Mance, 2002), ao defender a economia solidária, diz que, para que o Brasil a alcance, seria necessário que os componentes da relação econômica agissem de forma cooperativa, em iguais condições de soberania e de igualdade nas relações 
NASCIMENTO, Anna Melissa Marcondes; HUDSON, Maria Rita Cerqueira; SILVA, Antonio Wardison Canabrava. A base Constitucional como mecanismo de justiça para uma economia solidária.

econômicas, exercendo atividades complementares entre si: "para que tivéssemos uma sociedade em que predominasse a igualdade entre todos os seus membros, seria preciso que a economia fosse solidária em vez de competitiva. Isso significa que os participantes na atividade econômica deveriam cooperar entre si em vez de competir" (Mance, 2002, p.9).

\section{A economia solidária no Brasil}

De forma a contextualizar a economia solidária condizente com os conceitos constitucionais de justiça, faz-se necessária uma análise de ações de empreendimento social realizadas pelo governo brasileiro, que promovem os princípios de um desenvolvimento socioeconômico solidário. Entre os órgãos nacionais que dizem respeito à economia solidária, citamos o Fórum Brasileiro de Economia Solidária (FBES), a Secretaria Nacional de Economia Solidária (Senaes) e o Sistema Nacional de Informações em Economia Solidária (SIES).

Como esforço para o desenvolvimento econômico solidário no Brasil, o Ministério do Trabalho e Emprego (MTE) criou, em 2003, a Senaes, executando políticas públicas através de transferência de recursos a estados, municípios, universidades e organizações da sociedade civil com projetos de empreendimento solidário (Secretaria do Trabalho, 2016). Foi ela a responsável pela criação do programa "Economia Solidária em Desenvolvimento", colocandoo em plano plurianual, apresentando a finalidade de promover empreendimentos de autogestão e organizar a gestão de trabalhadores quanto à renda (Amorim, 2004).

Juntamente, no mesmo ano, foi instituído o Conselho Nacional de Economia Solidária (CNES) como órgão consultivo e propositivo para a interlocução entre setores governamentais e da sociedade civil, atuantes em favor da economia solidária. Em sua composição, envolvemse 56 entidades, dentre as quais o governo, empreendimentos de economia solidária e entidades não governamentais de atuação em prol da economia solidária (Secretaria do Trabalho, 2016).

Em 2006, o Presidente assinou o Decreto $\mathrm{n}^{\circ}$ 5811, dispondo sobre a composição, estruturação e funcionamento do CNES. Conforme o art. 2 do Decreto, a sua competência abrange o estímulo à participação da sociedade civil e do Governo no âmbito da economia solidária; a proposição de diretrizes em prol do movimento e a proposição de medidas para o aperfeiçoamento da legislação, fortalecendo a economia solidária no Brasil (Brasil, 2006).

O FBES surgiu em janeiro de 2001, e foi um grande pontapé para o movimento socioeconômico brasileiro como ferramenta de articulação e diálogo entre movimentos socialmente empreendedores, dando suporte a políticas públicas. O FBES, originado no Grupo 
NASCIMENTO, Anna Melissa Marcondes; HUDSON, Maria Rita Cerqueira; SILVA, Antonio Wardison Canabrava. A base Constitucional como mecanismo de justiça para uma economia solidária.

de Trabalho Brasileiro de Economia Solidária, foi formado pelas seguintes redes e entidades: Rede Brasileira de Socioeconomia Solidária (RBSES); Instituto Políticas Alternativas para o Cone Sul (PACS); Federação de Órgãos para a Assistência Social e Educacional (FASE); Associação Nacional dos Trabalhadores de Empresas em Autogestão (Anteag); Instituto Brasileiro de Análises Socioeconômicas (IBASE); Cáritas Brasileira; Movimento dos Trabalhadores Sem Terra (MST/Concrab); Rede Universitária de Incubadoras Tecnológicas de Cooperativas Populares (Rede ITCPs); Agência de Desenvolvimento Solidário (ADS/CUT); Unitrabalho; Associação Brasileira de Instituições de Micro-Crédito (Abicred) (Fórum Brasileiro de Economia Solidária, 1016). A organização do FBES se pauta em mais de 160 fóruns municipais, microrregionais e estaduais, além de envolver mais de 3 mil empreendimentos de economia solidária, 500 entidades de assessoria, 12 governos estaduais e 200 municípios pela Rede de Gestores em Economia Solidária.

As finalidades do FBES se baseiam na articulação de políticas públicas em prol da economia solidária, dialogando e liderando movimentos sociais, e no apoio ao movimento, dando suporte a fóruns municipais, regionais e estaduais de economia solidária, para que sejam a força que move e pauta a economia solidária como perspectiva de desenvolvimento sustentável para o país (Fórum Brasileiro de Economia Solidária, 1016).

O SIES é resultado do mapeamento que foi realizado conforme o Programa Economia Solidária em Desenvolvimento da Senaes sobre a economia solidária no Brasil. O SIES contém um banco de dados dos empreendimentos de economia solidária no país, que busca identificar e categorizar estas entidades para construir um retrato do estado do Brasil neste ramo da economia (SIES, 2020). Além disso, o SIES conta com outros objetivos:

Fortalecer a organização e integrar redes de produção, comercialização e consumo; promover o comércio justo e o consumo ético; subsidiar a formulação de políticas públicas; facilitar a realização de estudos e pesquisas; dar visibilidade à economia solidária para obter reconhecimento e apoio público. (Sistema Nacional de Informações em Economia Solidária, 2020, p.1)

Em 2013, a base de dados do SIES mapeou mais de 33 mil empreendimentos de economia solidária no país, sendo a maior parte deles registrados como associações (60\%) e localizados na região nordeste $(40,8 \%)$. O SIES ainda ressalta que os maiores desafios dos empreendimentos se voltam para uma geração de renda adequada para os sócios e a viabilidade econômica, mas constam outros, como a união dos grupos, efetivando a participação e autogestão, etc. Entre as conquistas, ressaltaram-se a integração coletiva, a geração de renda, o 
NASCIMENTO, Anna Melissa Marcondes; HUDSON, Maria Rita Cerqueira; SILVA, Antonio Wardison Canabrava. A base Constitucional como mecanismo de justiça para uma economia solidária.

exercício da democracia, a obtenção de conquistas para a comunidade local, entre outras (Senaes, 2013).

O desenvolvimento socioeconômico solidário no Brasil tem uma base forte estabelecida em diversos órgãos governamentais e entidades não governamentais, de caráter empreendedor, que fortalecem os princípios da economia solidária com políticas nacionais de criação e fiscalização de ações. Dentre os esforços do Governo Federal em implementar o movimento solidário, como meio de promoção da justiça social, há de se citar o papel de tornar acessíveis direitos fundamentais que concedem uma vida digna perante a lei.

\section{Conclusão}

Ainda que de significado polissêmico - na perspectiva do direito constitucional - a justiça, em regra, deve garantir os direitos fundamentais da pessoa e, com isso, da sua coletividade; deve, notavelmente, promover a harmonia social. Entende-se, ainda, como mecanismo positivo de o indivíduo se defender de abusos contra seus direitos. No campo propriamente dos direitos humanos, a justiça evidencia-se como direitos dados aos indivíduos, para que vivam com dignidade em um Estado de Direito.

Nesse horizonte, a economia solidária surge, como observa Singer, em resposta à desigualdade social e à pobreza, na tentativa de promover uma interação desinteressada e altruísta na sociedade. Nela, ao contrário do sistema capitalista, deve prevalecer uma concepção de justiça preocupada em maximizar a quantidade e qualidade de trabalho, visando o bem-estar de todos. O Estado, além de agir contra a desigualdade social, deve - como assegurado na Constituição de 1988 -, possibilitar uma economia justa. Assim, justiça e economia solidária, se complementares, poderão criar e sustentar a igualdade entre todos e, com isso, a garantia dos direitos fundamentais dos cidadãos e bem-estar coletivo.

No Brasil, vários órgãos nacionais governamentais e não governamentais - alguns referenciados neste ensaio -, instituem e promovem, em uma perspectiva empreendedora, a economia solidária, com políticas e ações diversas. E não pode ser outro o caminho, a não ser este capaz de, não somente acusar, com base na Constituição, a necessidade de uma economia solidária, mas também de oportunizar ações propositivas, de relevante impacto social, para que a justiça - garantida sua eficácia em um Estado de Direito -, sustente uma economia solidária. 


\section{Referências bibliográficas}

AMORIM, Brunu Marcus F.; ARAÚJO, Herton, Ellery. Economia Solidária no Brasil: novas formas de relação de trabalho? 2004. Disponível em: <http://repositorio.ipea.gov.br/bitstream/11058/5251/1/bmt_n.24_economiasolidbrasil.pdf > Acesso em: 4 nov 2020.

BRASIL. Decreto n. 5.811, 21 de junho de 2006. Dispõe sobre a composição, estruturação, competência e funcionamento do Conselho Nacional de Economia Solidária - CNES: Brasília, 2006. Disponível em: <http://www.planalto.gov.br/ccivil_03/_ato20042006/2006/decreto/d5811.htm>. Acesso em: 4 nov 2020.

BRASIL. Constituição Federal de 1988. Disponível em: <https://www.senado.leg.br/atividade/const/con1988/COM1988_05.10.1988/art_205_.asp>. Acesso em: 12 set 2020.

FÓRUM BRASILEIRO DE ECONOMIA SOLIDÁRIA. Resgatando a história do Fórum Brasileiro de Economia Solidária. FBES, 2016. Disponível em: <https://fbes.org.br/linha-detempo/> Acesso em: 4 nov 2020.

GUIMARÃES, Ulysses. Presidente da Assembleia Nacional Constituinte Discurso de promulgação da Constituição Federal. Disponível em: $<$ https://www.camara.leg.br/radio/programas/277285-integra-do-discurso-presidente-daassembleia-nacional-constituinte-dr-ulysses-guimaraes-10-23/> Acesso em: 12 set 2020.

MANCE, Euclides André. Redes de Colaboração Solidária. Curitiba: IFiL, 2002.

RODRIGUEZ, Arthur Fernandes Guimarães; DELGADO, Robson da Silva; LIMA, Rafael Alves. Etimologia jurídica. Jus, $[s$. l. $]$, fev 2016. Disponível em: https://jus.com.br/artigos/46600/etimologia-juridica. Acesso em: 17 out. 2020.

SECRETARIA DO TRABALHO. Conselho Nacional de Economia Solidária (CNES). 2016. Disponível em: <https://www.gov.br/trabalho/pt-br/assuntos/trabalhador/economiasolidaria/programas-e-acoes >. Acesso em: 6 nov 2020.

. Programas e Ações. 2016. Disponível em: <https://www.gov.br/trabalho/ptbr/assuntos/trabalhador/economia-solidaria/programas-e-acoes>. Acesso em: 4 nov 2020.

SENAES, Sistema Nacional de Informações em Economia Solidária - SIES - disponibiliza nova base de dados. Acontece Senaes, 2013. Disponível em: <https://web.archive.org/web/20140513184524/http://portal.mte.gov.br/data/files/8A7C816A 416FABB6014173C4E66C7839/Acontece\%20SENAES\%202013\%20-

$\% 20$ n34\%20ed\%20espercial.pdf $>$. Acesso em: 5 out 2020.

SIES, Sistema Nacional de Informação em Economia solidária. 2020. Disponível em: <http://sies.ecosol.org.br/sies?fbclid=IwAR1TTQM80WeRx4uC6ikRaKoN8PfAdQ4Obygq2 6xTQxit0OCRR3B-VY_Q31M> Acesso em: 4 nov 2020. 
NASCIMENTO, Anna Melissa Marcondes; HUDSON, Maria Rita Cerqueira; SILVA, Antonio Wardison Canabrava. A base Constitucional como mecanismo de justiça para uma economia solidária.

SINGER, Paul. A recente ressurreição da economia solidária no Brasil. In: SANTOS, B. S. Produzir para viver: os caminhos da produção não capitalista. Rio de Janeiro: Civilização Brasileira, [s.d]. Disponível em: <http://base.socioeco.org/docs/ecosolv2.pdf\#page=4> Acesso em: 9 out 2020.

Economia solidária versus economia capitalista. Soc. estado, Brasília, v.16, n.1-2, p.100-112, dez 2001. Disponível em: $<$ http://www.scielo.br/scielo.php?script=sci_arttext\&pid=S010269922001000100005\&lng=en\&nrm=iso>. Acesso em: 4 nov 2020.

Introdução à economia solidária. São Paulo: Fundação Perseu Abramo, 2002.

VIEIRA, Oscar Vilhena. A constituição como reserva de justiça. Lua Nova, São Paulo, n.42, $1997 . \quad$ Disponível em: https://www.scielo.br/scielo.php?pid=S010264451997000300003\&script=sci_arttext\&tlng=pt\#nt. Acesso em: 1 out 2020. 